\title{
Relationship between Physical Activity Level, Hepatic Steatosis Presence, Metabolic Syndrome and the Risk of Developing Type 2 Diabetes in Men
}

\section{Carla Giuliano de Sá Pinto Montenegro",2, Marcio Marega1, José Antonio Maluf de Carvalho, Luis Felipe Tubagi Polito², Rafael Mathias Pitta², Fabio Luis Ceschini², Danilo Sales Bocalini², Aylton José Figueira Junior²}

\author{
${ }^{1}$ Albert Einstein Israelita Hospital, São Paulo, Brazil \\ ${ }^{2}$ São Judas Tadeu University, São Paulo, Brazil \\ Email: carla.pinto@einstein.br
}

How to cite this paper: Montenegro, C.G.P., Marega, M., de Carvalho, J.A.M., Polito, L.F.T., Pitta, R.M., Ceschini, F.L., Bocalini, D.S. and Junior, A.J.F. (2016) Relationship between Physical Activity Level, Hepatic Steatosis Presence, Metabolic Syndrome and the Risk of Developing Type 2 Diabetes in Men. Health, 8, 1778-1787. http://dx.doi.org/10.4236/health.2016.815171

Received: October 6, 2016

Accepted: December 11, 2016

Published: December 14, 2016

Copyright $\odot 2016$ by authors and Scientific Research Publishing Inc. This work is licensed under the Creative Commons Attribution International License (CC BY 4.0).

http://creativecommons.org/licenses/by/4.0/

(c) (i) Open Access

\begin{abstract}
Cardiovascular disease, cancer, respiratory and metabolic disease represent $63 \%$ of all deaths worldwide and are considered the major causes of morbidity and mortality. Physical inactivity is considered a case of public health, and other behavioral and metabolic risk factors, according to WHO (2011), such as smoking, increased blood pressure, increased blood glucose, hypercholesterolemia, overweight and obesity. The Nonalcoholic Fatty Liver Disease (NAFLD) is the most prevalent liver disease in adults, and can progress and be characterized as hepatic steatosis (HS) which is derived from the accumulation of lipids in hepatocytes, and histopathologic condition is more than $5 \%$ of the weight of liver. So, the purpose of this study is to identify the relationship between the physical activity level and the hepatic steatosis presence, metabolic syndrome and the risk of developing type 2 diabetes mellitus in men. We evaluated retrospectively medical records of 1399 men ( $40.7 \pm 8.18$ years old) who participated in the protocol of Preventive Health Check-up at Hospital Israelita Albert Einstein from January to October 2011. According to the results, it is concluded that there is a positive association between low physical activity level and the presence of Hepatic steatosis. The results further demonstrate that, despite the high BMI, blood levels of the subjects remained unchanged. Even without a positive association between these variables, the results showed a high risk behavior for the development of diabetes mellitus type 2 .
\end{abstract}

\section{Keywords}

Physical Activity, Hepatic Steatosis, Metabolic Syndrome, Type 2 Diabetes 


\section{Introduction}

Cardiovascular disease, cancer, respiratory and metabolic disease represent $63 \%$ of all deaths worldwide and are considered the major causes of morbidity and mortality. Of the 36 million people who had deaths associated with chronic non-communicable diseases (NCDs), 9 million died before 60 years and $90 \%$ of premature deaths occurred in low- and middle-income countries [1].

Physical inactivity is considered a case of public health, inducing economic, behavioral and social problems, relating to 5.7 million deaths that are associated with NCDs [2], and other behavioral and metabolic risk factors, according to WHO [3], such as smoking, increased blood pressure, increased blood glucose, hypercholesterolemia, overweight and obesity.

According to HILL and WYATT [4], ECSS [5], ACSM [6], weight gain occurs as a result of an imbalance between energy intake and daily energy expenditure. Thus, the match between ingested caloric intake and caloric expenditure arising from physical activity (PA) daily would allow the loss and weight control, contributing factors in reducing risk and aggravation of health, although social, behavioral, environmental and genetic related factors can interfere in this context.

The Nonalcoholic Fatty Liver Disease [7] is the most prevalent liver disease in adults, and is characterized as a clinical-pathological condition of broad spectrum and high evolutionary potential [8]. NAFLD can progress and be characterized as hepatic steatosis (HS) which is derived from the accumulation of lipids in hepatocytes, and histopathologic condition is more than $5 \%$ of the weight of liver. The HS promotes liver damage, because it is considered one of the most common causes of chronic liver disease in adults living in developed and emerging countries. The world's population prevalence remains between $10 \%$ and $24 \%$ among adults of both sexes [9]. Because of metabolic changes resulting from HS, currently the HS is recognized as the common cause to the development of metabolic syndrome, including the Type 2 Diabetes Mellitus (DM2) development.

It is known that metabolic diseases are strongly associated with lifestyle, especially with the nutritional habits and physical activity practice. There are few studies about the relationship between risk factors, NCDs and NAFLD. So, the purpose of this study is to identify the relationship between the physical activity level and the hepatic steatosis presence, metabolic syndrome and the risk of developing type 2 diabetes mellitus in men.

\section{Methods}

We evaluated retrospectively medical records of 1399 men ( $40.7 \pm 8.18$ years old). The inclusion criteria were: men who participated in the protocol of Preventive Health Check-up at Hospital Israelita Albert Einstein from January to October 2011. Inclusion criteria were: Diagnosis of type 1 diabetes or type 2 diabetes, consumption of alcohol classified as intermediate to high. These individuals participants underwent several exams and evaluations including anthropometric, metabolic and serial measures. 
Anthropometric evaluation determined body mass $(\mathrm{kg})$, height $(\mathrm{cm})$, waist circumference $(\mathrm{cm})$ and body mass index $\left(\mathrm{kg} / \mathrm{m}^{2}\right)$.

Weight was determined using the Ottoboni Inbody 230 Body Composition Scale. In the weight evaluation, the individual was wearing light clothing and no shoes. Height was determined using a stadiometer with a $0.1 \mathrm{~mm}$ precision. Individuals were measured with heels, buttocks, scapula and occipital surface touching the wall. In addition, participant was making inspiratory apnea, looking ahead and, at this moment, the evaluator did the measurement placing the stadiometer on top of individual's head. The measure was done three times, and the final result was a mean of three measures.

Anthropometric values of body weight and height were used to calculate the body mass index $\left(\mathrm{BMI}=\mathrm{kg} / \mathrm{m}^{2}\right)$ that classified obesity according to 2004 guidelines stated by the World Health Organization [3] for adults, being: eutrophic if 18.5 to $24.9 \mathrm{~kg} / \mathrm{m}^{2}$, overweight if 25.0 to $29.9 \mathrm{~kg} / \mathrm{m}^{2}$, and obese if over $30.0 \mathrm{~kg} / \mathrm{m}^{2}$.

In the waist circumference measurement, the individual was kept in orthostatic position with relaxed abdomen. The tape measure was placed in horizontal plan in medium point between last costal arch and iliac crest. The final result was calculated based on the mean of three measurements previously conducted.

Systolic and diastolic blood pressure $(\mathrm{mmHg})$ were measured with patients seated after resting for 5 minutes, using appropriate cuff width in relation to patient arm circumference. The aneroid sphygmomanometer was previously calibrated, as stated by the guidelines of Brazilian Society of Hypertension [10] [11]. Other two measures were done in different moments, and mean value obtained was considered as the final value. In case of discrepant measures (different greater than $5 \mathrm{mmHg}$ ) the most close values were used to calculate the mean.

The serum assessment included in blood samples collected after a 12-hour fast. We obtained, using the methods listed below: dosages of total cholesterol, high density lipoprotein, triglycerides: enzymatic-dried chemical; uric acid: colorimetric (Uricase)Fusion-Dried chemical; Glycemia: Enzimatic (GOD-POD)-Fusion-Dried Chemical; high-density lipoprotein: measured by Friedewald formula; liver enzyme: Aspartate transaminase, Alanine transaminase, gammaglutamyl transpeptidase (AST, ALT, Gamma GT): Enzimatic-Fusion-Dried chemical, Reactive C-protein (RCP): Turbidimetry (Vitros Fusion 5.1 FS).

Fatty liver was considered present when it was detected by the abdominal ultrasonography, which evaluated the form and conservation of the liver. Individuals were classified as those who had fatty liver and those who had not fatty liver.

We classified as metabolic syndrome those individuals with three or more criteria based on Third Report of the Expert Panel on Detection, Evaluation, and Treatment of High Blood Cholesterol in Adults (Adult Treatment Panel III) [12].

The consume of alcohol was evaluated using the questionnaire of Alcohol Use Disorder Identification Test [13], that classifies in low, intermediate and high the daily alcohol consumption of these individuals, followed by WHO [3] recommendations on non-harm full consumption. 
The level of physical activity was determined by the short version of the International Physical Activity Questionnaire [14], fulfilled by physical educator during the Preventive Health Check-up consultation, being classified as active (ACT) those individuals who had 150 minutes of moderate-intensity physical activity weekly, insufficiently active (INSU) those who make 10 - 149 minutes of physical activity weekly and sedentary (SED) who do not realize 10 minutes of physical activity weekly.

The FINDRISC (Score Risk Finnish Diabetes) is a questionnaire formulated by J. Tuomilehto and Janna Lindström [15] used for stratifying the risk of developing type 2 diabetes, as well as detect this disease undiagnosed and insulin resistance. The criteria for classification are: age, body mass index, waist circumference, physical activity, consumption of fruits and vegetables, antihypertensive medication, the presence of occasional hyperglycemia during illness or pregnancy and family history [15] [16]. The FINDRISC identifies individuals at high risk for diabetes who most benefit from life style modification [17] and was applied stratifying individuals into low risk, moderate/intermediate, high/very high group.

All participants signed the consent term respecting ethical and legal aspects of research on human subjects, according to the Declaration of Helsinki. This study was approved by the Ethical Committee, protocol number CAAE: 28948314.1.0000.0071 and legal advice number 633.479. Data were analyzed using the Statistical Package for the Social Sciences (SPSS) version 17.0. Categorical variables were expressed in absolute variables and percentages. Continual variables were presented in means and standard deviations if parametrical or medium, if non-parametrical they were presented in minimal and maximal values. The comparison of continuing variables between two groups were done using the $t$ test or Mann-Whitney test, based on the nature of distribution.

\section{Results}

All individuals are Brazilian, in the middle and upper social classes (Table 1).

The prevalence of men diagnosed with HS was higher in INSU (62.08\%) and SED (27.07\%). The proportion of men diagnosed with metabolic syndrome was $29.63 \%$ SED, $52.60 \%$ INSU and $17.77 \%$ ACT.

The INSU men with High/Very High risk of developing Type 2 Diabetes Mellitus had a higher prevalence (48.54\%) than the SED (36.90\%). The SED subjects at low risk was $12.92 \%$, while INSU (41.96\%) and ACT (45.12\%) (Table 2).

The SED men had an average of Gamma GT $44.65 \mathrm{U} / \mathrm{L}( \pm 32.50)$ higher than the average of INSU and ACT men (39.14 \pm 28.36 and $36.36 \pm 47.74$ respectively), although they are within the normal values. Comparing liver enzyme AST there was no significant difference between the physical activity level. Regarding ALT enzyme, SED men had an average of $49.94 \mathrm{U} / \mathrm{L}( \pm 39.47)$, higher than the INSU $45.47 \mathrm{U} / \mathrm{L}( \pm 20.47)$ and ACT $40.56 \mathrm{U} / \mathrm{L}( \pm 17.94)$.

ACT men had average total cholesterol of $197.77 \mathrm{mg} / \mathrm{dL}$ and less than the SED and INSU, $208.57 \mathrm{mg} / \mathrm{dl}$ and $203.83 \mathrm{mg} / \mathrm{dL}$ respectively, within the threshold value, but 
above the desirable values.

The average value of triglycerides of SED was higher to the INSU and ACT men but all within the desirable pattern.

C Reactive Protein (CRP) is an inflammatory marker, used as a marker of cardiovascular risk. In SED and INSU individuals the average CRP approached the threshold value, suggesting increased cardiovascular risk (Table 3).

Table 1. Anthropometric, metabolic and serum profile of adult men.

\begin{tabular}{ccc}
\hline Variables & X & SD \\
\hline Age (years) & 40.7 & 8.0 \\
Body Weight (kg) & 83.9 & 12.4 \\
Stature (cm) & 177.4 & 6.4 \\
Body Mass Index (Kg/m $\left.{ }^{2}\right)$ & 26.7 & 3.4 \\
Waist Circumference (cm) & 94.9 & 9.6 \\
Systolic Blood Pressure (mmHg) & 117.4 & 10.7 \\
Diastolic Blood Pressure (mmHg) & 76.7 & 7.1 \\
Aerobic Power (MET) & 14.6 & 4.1 \\
Glicose & 88.0 & 9.2 \\
Total Cholesterol & 202.8 & 38.2 \\
High Density Lipoprotein & 46.0 & 10.3 \\
Low Density Lipoprotein & 129.5 & 34.3 \\
Triglycerides & 137.4 & 88.4 \\
Aspartate Transaminase & 30.9 & 19.2 \\
Alanine Transaminase & 44.4 & 25.3
\end{tabular}

Legend: X: average; SD: standard deviation.

Table 2. Relationship between physical activity level and metabolic indicators in men.

\begin{tabular}{cccc}
\hline & SED (\%) & INSU (\%) & ACT (\%) \\
\hline Hepatic Steatosis Presence & 27.07 & 62.08 & 10.85 \\
Hepatic Steatosis Absence & 15.23 & 39.35 & 45.42 \\
Metabolic syndrome Absence & 17.82 & 46.95 & 35.23 \\
Metabolic syndrome Presence & 29.63 & 52.60 & 17.77 \\
Findrisc Low & 12.92 & 41.96 & 45.12 \\
Findrisc Mod/Inter & 22.04 & 52.78 & 25.18 \\
Findrisc High/Very high & 36.90 & 48.54 & 14.56 \\
\hline
\end{tabular}

${ }^{*} \mathrm{p}<0.05$; Legend: SED: sedentary; INSU: insufficiently active; ACT: active. 
Table 3. Physical activity level and lipid profile in men.

\begin{tabular}{|c|c|c|c|c|}
\hline & & SED & INSU & ACT \\
\hline Gama gt (U/L) & $\mathrm{x}$ & 44.65 & 39.14 & 36.34 \\
\hline $15-73 \mathrm{U} / \mathrm{L}$ & s & 32.50 & 28.36 & 47.74 \\
\hline AST (U/L) & $\mathrm{x}$ & 31.17 & 30.99 & 31.56 \\
\hline $17-59 \mathrm{U} / \mathrm{L}$ & s & 16.44 & 14.68 & 22.77 \\
\hline $\operatorname{ALT}(\mathrm{U} / \mathrm{L})$ & $\mathrm{x}$ & $\underline{49.94}$ & $\underline{45.47}$ & $\underline{40.56}$ \\
\hline $21-72 \mathrm{U} / \mathrm{L}$ & $s$ & 39.47 & 20.47 & 17.94 \\
\hline Glycemia (mg/dL) & $\mathrm{x}$ & 88.24 & 88.75 & 86.86 \\
\hline $70-99 \mathrm{mg} / \mathrm{dL}$ & $s$ & 9.53 & 10.08 & 8.79 \\
\hline Total Cholesterol (mg/dL) & $\mathrm{x}$ & 208.57 & 203.83 & 197.77 \\
\hline$<200 \mathrm{mg} / \mathrm{dL}$ & $s$ & 39.00 & 37.11 & 38.41 \\
\hline HDL Cholesterol (mg/dL) & $\mathrm{x}$ & $\underline{43.56}$ & $\underline{45.84}$ & $\underline{48.84}$ \\
\hline$\geq 40 \mathrm{mg} / \mathrm{dL}$ & s & 8.88 & 9.94 & 11.43 \\
\hline LDL Cholesterol (mg/dL) & $\mathrm{x}$ & $\underline{159.16}$ & $\underline{144.80}$ & $\underline{122.89}$ \\
\hline$<130 \mathrm{mg} / \mathrm{dL}$ & $s$ & 34.32 & 33.61 & 33.79 \\
\hline Triglycerides (mg/dL) & $\mathrm{x}$ & $\underline{133.81}$ & $\underline{129.27}$ & $\underline{125.23}$ \\
\hline$<150 \mathrm{mg} / \mathrm{dL}$ & $s$ & 103.29 & 94.24 & 109.19 \\
\hline C-Reactive Protein $(\mathrm{mg} / \mathrm{dL})$ & $\mathrm{x}$ & $\underline{2.20}$ & $\underline{2.21}$ & $\underline{1.36}$ \\
\hline $0-3.0 \mathrm{mg} / \mathrm{dL}$ & $\mathrm{s}$ & 3.37 & 4.20 & 2.09 \\
\hline
\end{tabular}

${ }^{*} \mathrm{p}<0.05$; Legend: SED: sedentary; INSU: insufficiently active; ACT: active

\section{Discussion}

The relationship between the physical activity level and metabolic indicators, among men who had HS, only $10.85 \%$ are ACT; the prevalence was among the INSU groups (62.08\%) and SED (27.07\%), showing that physical activity interfere in fat metabolism, helping to prevent metabolic disorders.

Adams et al. [7] state that metabolic changes, especially metabolic syndrome represent the beginning of the HS development process; since the physical activity interfere with the metabolic syndrome predisposing factors such as lipid levels showed changes between different physical activity level. In the present study we hypothesize that physical activity can be considered preventive factor for the development of HS.

One of the explanations related to the benefits of physical activity in subjects with HS refers to the positive effect in increasing the oxidation of fatty acids by the liver during aerobic activities at moderate/vigorous intensities [18]. BELMONTE et al. [19] reported that after exercise session, the hepatic lipid metabolism responsible for the replacement of intramuscular triglycerides, especially in patients wherein the process is destabilized such as obesity.

Cho et al. [20] studied the effect of training intensity on NAFLD, analyzing for this C57BL/6mice. The mice were submitted to high fat diet with or without exercise. The 
authors worked with two exercises models: vigorous intensity (twelve 1-min intervals at $17 \mathrm{~m} / \mathrm{min}$ with 2 -min active recovery at $10 \mathrm{~m} / \mathrm{min}$ between intervals; 5 days/week) and moderate intensity ( $45 \mathrm{~min}$ at $10 \mathrm{~m} / \mathrm{min}$ ). The training load was equalized through the running distance $(524 \mathrm{~m})$. The results signaled that the vigorous intensity was more effective for NAFLD control.

The exercises with more vigorous intensity are associated with greater activation on hepatic AMP-mediated protein kinase, following the greater suppressive effect on hypoadiponectinemia and down regulation of the Adiponectin receptor 2, which is interesting to diabetes type 2 treatment too [20].

Onnerhag, Nilsson \& Lindgren [21] analyzed the association between insulin resistance and NAFLD and found interesting results. Liver steatosis showed significantly correlation with ALT (alanine aminotransferase), HOMA-IR and the metabolic syndrome and $80 \%$ of the subjects with NAFLD had either developed type 2 diabetes mellitus or other impaired fasting glucose. When was analyzed the WHO-criteria for the metabolic syndrome, there was significantly difference between hepatic steatosis group and non-hepatic steatosis group.

Long et al. [22] evaluated the relationship between physical activity level (mensured via Accelerometry) and hepatic steatosis in a cross-sectional study of 1060 participants. The authors observed inverse association between two variables, the $30 \mathrm{~min} /$ day increase in moderate/vigorous physical activity was associated with a reduction of hepatic steatosis odds.

The benefits to NAFLD treatment could have been occurred by weight loss too, an important intervention for these patients [23].

The general caloric restriction is related with: reduction of triacylglycerols, reduction of hepatic insulin resistance, reduction of glucose output, reduction of reactive oxygen species, reduction of hepatocyte inflammation, reduction of de novo lipogenesis, increasing of leptin sensitivity and of adiponectin level [24].

Although there is still no consensus on the specific pharmacological treatment in the control of NAFLD, the reduction fat intake and the involvement in a regular physical exercise program induce weight reduction and improved lipid profile, being effective in metabolic syndrome and NAFLD control [18]. ADAM et al. [7]; stated that weight loss and physical exercise reduced insulin resistance. For people with Diabetes Type I (independent of the age), the regular exercise can reduce the insulin daily needs, showing improve the glycemic control in these patients [25].

According to CARVALHEIRA et al. [26], ACHTEN, SUTEDJA \& JEUKENDRUP [27], the lifestyle habits such as diet and physical activity may interfere with factors associated with the development of metabolic syndrome. When we analyze the relationship between the presence of metabolic syndrome and the physical activity level in the present study, we emphasize the role of physical activity as a preventive factor for metabolic disorders. Only $17.77 \%$ of men with metabolic syndrome perform physical activity regularly, then showing an inverse relationship between the presence of metabolic syndrome, DM risk development and physical activity regular practice. 
Recently, Hashida et al. [28] published a systematic review about the influence of resistance and aerobic exercise in NAFLD patients. The aerobic exercise can induce activation of lipolysis, up-regulation of UCP-1 and PPARy and alteration in adipocytokine, while the resistance training can induce hypertrophy of type 2 muscle fibers, activation of Glut-4, AMPK, caveolins and alteration in myokines. The aerobic training (media effective protocol was: intensity: $4.8 \mathrm{METs}$; duration: $40 \mathrm{~min} / \mathrm{session}$; frequency: 3 times/week; program length: 12 weeks) induced more energy consumption and higher $\% \mathrm{VO}_{2 \text { máx }}$ than resistance training. However, the resistance training could be indicated to patients with poor cardiorespiratory fitness or patients that cannot tolerate or participate in aerobic exercise.

\section{Conclusion}

According to the above results, it is concluded that there is a positive association between low physical activity level and the presence of hepatic steatosis. The results further demonstrate that, despite the high BMI, blood levels of the subjects remained unchanged. Even without a positive association between these variables, the results showed a high risk behavior for the development of diabetes mellitus type 2 .

\section{References}

[1] Pratt, M., Sarmiento, O.L., Montes, F., Ogilvie, D., Marcus, B.H., Perez, L.G., et al. (2012) The Implications of Megatrends in Information and Communication Technology and Transportation for Changes in Global Physical Activity. The Lancet, 380, 282-293. https://doi.org/10.1016/S0140-6736(12)60736-3

[2] Kohl, H.W., Craig, C.L., Lambert, E.V., Inoue, S., Alkandari, J.R., Leetongin, G., et al. (2012) The Pandemic of Physical Inactivity: Global Action for Public Health. The Lancet, 380, 294-305. https://doi.org/10.1016/S0140-6736(12)60898-8

[3] World Health Organization (2011) Noncommunicable Diseases Country Profiles 2011. World Health Organization, Geneva.

[4] Hill, J.O. and Wyatt, H.R. (2005) Role of Physical Activity in Preventing and Treating Obesity. Journal of Applied Physiology, 99, 765-770. https://doi.org/10.1152/japplphysiol.00137.2005

[5] Fogelholm, M., Stallknecht, B. and Van Baak, M. (2006) ECSS Position Statement: Exercise and Obesity. European Journal of Sport Science, 6, 15-24. https://doi.org/10.1080/17461390600563085

[6] Donnelly, J.E., Blair, S.N., Jakicic, J.M., Manore, M.M., Rankin, J.W. and Smith, B.K. (2009) American College of Sports Medicine Position Stand. Appropriate Physical Activity Intervention Strategies for Weight Loss and Prevention of Weight Regain for Adults. Medicine and Science in Sports and Exercise, 41, 459-471. https://doi.org/10.1249/MSS.0b013e3181949333

[7] Adams, L.A., Angulo, P. and Lindor, K.D. (2005) Nonalcoholic Fatty Liver Disease. Canadian Medical Association Journal, 172, 899-905. https://doi.org/10.1503/cmaj.045232

[8] Cotrim, H.P. (2009) Doença Hepática Gordurosa Não-Alcoólica: História Natural. Gazeta médica da Bahia, 79, 46-47.

[9] Soler, G.L.N., Silva, A., Silva, V.C.G. and Teixeira, R.J. (2008) Doença hepática gordurosa não-alcoólica: Associação com síndrome metabólica e fatores de risco cardiovascular. $R e$ - 
vista da SOCERJ, 21, 94-100.

[10] Mion Jr., D.., Machado, C.A., Gomes, M.A.M., et al. (2004) IV Brazilian Guidelines in Arterial Hypertension. Arquivos brasileiros de cardiologia, 82, 7.

[11] Perloff, D., Grim, C., Flack, J,, Frohlich, E.D., Hill, M., McDonald, M., et al. (1993) Human Blood Pressure Determination by Sphygmomanometry. Circulation, 88, 2460-2470. https://doi.org/10.1161/01.CIR.88.5.2460

[12] Expert Panel on Detection, Evaluation, and Treatment of High Blood Cholesterol in Adults (2001) Executive Summary of the Third Report of the National Cholesterol Education Program (NCEP) Expert Panel on Detection, Evaluation, and Treatment of High Blood Cholesterol in Adults (Adult Treatment Panel III). JAMA, 285, 2486-2497.

https://doi.org/10.1001/jama.285.19.2486

[13] Saunders, J.B., Aasland, O.G., Babor, T.F., de la Fuente, J.R. and Grant, M. (1993) Development of the Alcohol Use Disorders Identification Test (AUDIT): WHO Collaborative Project on Early Detection of Persons with Harmful Alcohol Consumption-II. Addiction, 88, 791-804. https://doi.org/10.1111/j.1360-0443.1993.tb02093.x

[14] Matsudo, S., Araújo, T., Marsudo, V., Andrade, D., Andrade, E. and Braggion, G. (2001) Questinário internacional de atividade f1sica (IPAQ): Estudo de validade e reprodutibilidade no Brasil. Rev bras ativ fís saúde, 6, 5-18.

[15] Lindström, J. and Tuomilehto, J. (2003) The Diabetes Risk Score. Diabetes Care, 26, 725731. https://doi.org/10.2337/diacare.26.3.725

[16] Schwarz, P.E., Li, J., Reimann, M., Schutte, A.E., Bergmann, A., Hanefeld, M., et al. (2009) The Finnish Diabetes Risk Score Is Associated with Insulin Resistance and Progression towards Type 2 Diabetes. The Journal of Clinical Endocrinology \& Metabolism, 94, 920-926. https://doi.org/10.1210/jc.2007-2427

[17] Lindström, J., Peltonen, M., Eriksson, J.G., Aunola, S., Hämäläinen, H., Ilanne-Parikka, P., et al. (2008) Determinants for the Effectiveness of Lifestyle Intervention in the Finnish Diabetes Prevention Study. Diabetes Care, 31, 857-862. https://doi.org/10.2337/dc07-2162

[18] Rector, R.S., Thyfault, J.P., Morris, R.T., Laye, M.J., Borengasser, S.J., Booth, F.W., et al. (2008) Daily Exercise Increases Hepatic Fatty Acid Oxidation and Prevents Steatosis in Otsuka Long-Evans Tokushima Fatty Rats. American Journal of Physiology-Gastrointestinal and Liver Physiology, 294, G619-G626. https://doi.org/10.1152/ajpgi.00428.2007

[19] Belmonte, M.A., Aoki, M.S., Tavares, F.L. and Seelaender, M.C. (2004) Rat Myocellular and Perimysial Intramuscular Triacylglycerol: A Histological Approach. Medicine and Science in Sports and Exercise, 36, 60-67. https://doi.org/10.1249/01.MSS.0000106170.26822.55

[20] Cho, J., Kim, S., Lee, S. and Kang, H. (2015) Effect of Training Intensity on Nonalcoholic Fatty Liver Disease. Medicine and Science in Sports and Exercise, 47, 1624-1634. https://doi.org/10.1249/MSS.0000000000000595

[21] Önnerhag, K., Nilsson, P.M. and Lindgren, S. (2013) Insulin Resistance with Impaired Fasting Glucose Increases the Risk of NAFLD. Open Journal of Gastroenterology, 3, 170176. https://doi.org/10.4236/ojgas.2013.33028

[22] Long, M.T., Pedley, A., Massaro, J.M., Hoffmann, U., Esliger, D.W., Vasan, R.S., et al. (2015) Hepatic Steatosis Is Associated with Lower Levels of Physical Activity Measured via Accelerometry. Obesity, 23, 1259-1266. https://doi.org/10.1002/oby.21058

[23] Wang, R.T., Koretz, R.L. and Yee, H.F. (2003) Is Weight Reduction an Effective Therapy for Nonalcoholic Fatty Liver? A Systematic Review. The American Journal of Medicine, 115, 554-559. https://doi.org/10.1016/S0002-9343(03)00449-2

[24] Harrison, S.A. and Day, C.P. (2007) Benefits of Lifestyle Modification in NAFLD. Gut, 56, 
1760-1769. https://doi.org/10.1136/gut.2006.112094

[25] Iughetti, L., Gavioli, S., Bonetti, A. and Predieri, B. (2015) Effects of Exercise in Children and Adolescent with Type 1 Diabetes Mellitus. Health, 7, 1357-1365.

https://doi.org/10.4236/health.2015.710150

[26] Carvalheira, J.B. and Saad, M.J. (2006) Doenças associadas à resistência à insulina/ hiperinsulinemia, não incluídas na síndrome metabólica. Arquivos Brasileiros de Endocrinologia \& Metabologia, 50, 360-367. https://doi.org/10.1590/S0004-27302006000200022

[27] Achten, J., Sutedja, D., Johnson, J., Jeukendrup, A., Jones, D. and Elias, E. (2003) Treatment of Nonalcoholic Steatohepatitis: The Effects of Regular Exercise. European Journal of Sport Science, 3, 1-13. https://doi.org/10.1080/17461390300073404

[28] Hashida, R., Kawaguchi, T., Bekki, M., Omoto, M., Matsuse, H., Nago, T., et al. (2016) Aerobic vs. Resistance Exercise in Non-Alcoholic Fatty Liver Disease: A Systematic Review. Journal of Hepatology. https://doi.org/10.1016/j.jhep.2016.08.023

Submit or recommend next manuscript to SCIRP and we will provide best service for you:

Accepting pre-submission inquiries through Email, Facebook, LinkedIn, Twitter, etc. A wide selection of journals (inclusive of 9 subjects, more than 200 journals)

Providing 24-hour high-quality service

User-friendly online submission system

Fair and swift peer-review system

Efficient typesetting and proofreading procedure

Display of the result of downloads and visits, as well as the number of cited articles Maximum dissemination of your research work

Submit your manuscript at: http://papersubmission.scirp.org/

Or contact health@scirp.org 